Health

Education in

Practice:

Journal

Research of

Professional

Learning

Vol. 2 | No. 2 | 2019

\section{Education-in-}

practice article (single blind peer-review)

\section{(c) $\$(0)$}

Copyright is held by the authors with the first publication rights granted to the journal. Conditions of sharing are defined by the Creative Commons License

Attribution-

ShareAlike-

NonCommercial 4.0 International

Citation: Larmer, $P$, Smythe, E \& Jones, M 2019, 'Professional doctorates:

grasping a new way', Health Education in Practice: Journal of Research for Professional

Learning, vol. 2, no.

\section{2}

http://dx.doi.org /10.33966/hepj.2. 2.13348

\section{Professional doctorates:} grasping a new way

\author{
Peter J Larmer(iD) ${ }^{1}$, Elizabeth Smythe(iD) ${ }^{1}$,
} Marion Jones ${ }^{1}$

\section{Abstract}

It is one thing to create the curriculum for a professional doctorate with a graduate profile that talks of practice change and leadership development. Our experience in initiating the Doctor of Health Science in 2002 at the Auckland University of Technology (AUT) was that it was all too easy to fall back on the PhD mindset. We took inspiration from the literature and pioneering candidates to show us how this program could be distinctively different from a PhD. We tell our story to reveal both the challenges and possibilities involved, and to recognise that all of our candidates are focused on bringing change to practice. some do this through research 'on' practice, others by research 'in' practice, and then there are those caught up in the research-practice nexus. We believe a professional doctorate program has the potential to significantly develop these candidates into leaders of practice change.

Keywords: professional doctorates, practice-led research, changing practice.

1 Auckland University of Technology, Auckland, New Zealand

Corresponding author: Peter J Larmer, Associate Professor and Head, School of Clinical Sciences; Te Kura Mātai Haumanu, AUT University; Te Wānanga Aronui o Tāmaki Makau Rau, Auckland, New Zealand, Email: Peter.larmerlaut.ac.nz 


\title{
PROFESSIONAL DOCTORATES: GRASPING A NEW WAY
}

\author{
'To work within a tradition (to acquire such a style, or \\ to copy an archaic, existing style) is relatively easy. To \\ introduce a new style-in other words, a new way of seeing- \\ is not.' (Fish 2009, p. 135)
}

In 2002, we had the privilege of leading the development of a professional doctorate at the Auckland University of Technology (AUT). Deemed the Doctor of Health Science (DHSC), the program first welcomed nine enrolments from students spanning multiple health disciplines. In 2018, there were 31 enrolments, a total cohort of 114 , with a total of 38 graduates to date. Over the years, a new way of observing what constitutes a professional doctorate program has since emerged. Now, we seek to articulate our growing understanding of what we aim to achieve with our program, how we go about its process and how one can recognise the various challenges involved. The aim of this paper is to encourage others on their own journey of establishing a professional doctorate program. While the arguments presented are contextualised in health, the experience is likely to be similar for other practice-based disciplines.

\section{UNDERSTANDING THE NATURE OF A PROFESSIONAL DOCTORATE}

Six years into our DHSc program our external reviewer asked us, how is a DHSC thesis different from a PhD? The easy answer is study length-that is, three years for a PhD thesis and 3.5 years for the DHSc. This consists of a thesis equivalent to two years of full-time study, plus three preparatory papers over three semesters. We soon realised that apart from the time required for completion, there was little distinguishing difference in our thinking for each doctorate, other than one began with three papers. We still held a strong academic focus, turning the candidates' attention to the literature and philosophy, expecting a thesis two thirds the size of a PhD but otherwise similar in substance. That got us thinking, reading and exploring the possibilities of how a professional doctorate might be more relevant to the practitioners enrolling in the program.

Discovering the work of Rolfe and Davies (2009) became a key catalyst in differentiating the two. They described the PhD as 'mode one' knowledge, which arises from expectations of a given university, conforms to traditional research methods and makes a contribution to knowledge. In contrast, 'mode two' knowledge production is akin to a professional 
doctorate and brings a research interest from practice. The research approach is likely to be collaborative with stakeholders, emergent and shaped by context. As such, candidates must be responsive and able to adapt to the dynamic and unfolding nature of practice, as the key contribution such theses make regards the direct application of knowledge to practice. Suddenly, it was clear that our taken-for-granted method of deliberating what constitutes a thesis and how it is conducted needed to change.

Reading about the differences and enacting them in practice are two different things. This process has been an ongoing experience hinged on thinking and rethinking, as well as building understanding from several directions. First, Professor Gary Rolfe spent a week with us in our program, offering invaluable guidance and critique. Peter (a co-author of this paper) attended two professional doctorate conferences in the United Kingdom (2014 and 2018) and returned both excited by the move to practice-led theses and concerned at the challenges of having such work 'understood' by examiners. We received ongoing feedback from stakeholders in practice that change was taking place. Concurrently, we had our own experience with bold candidates doing authentic practice-led theses, and noticed that their efforts seemed to be well supported by managers. We were encouraged and excited by the significant effect these research projects were having on practice through the thesis journey, as well as the impressive leadership growth of each candidate. However, examiners did not receive every thesis with insight as to the nature of Rolfe and Davies's (2009) 'mode two' knowledge production. Examiners came with the expectation that the thesis would privilege the contribution to knowledge, and tended to almost overlook the effect on practice and on the leadership development of candidates. Thus, we needed guidance from colleagues on similar quests in discerning the value and pitfalls of practice-led theses.

One key article that echoed our growing sense of 'what matters' focused on 'work-based' doctorates-a term with which we were unfamiliar. This definition resonated, causing us to emphasise the following keywords:

\footnotetext{
'At a practical level it will be concerned with working at and extending the leading edge of a professional or organisational field, with significant impacts in both the candidate's profession or community of practice and in terms of his or her personal professional development.' (Costley \& Lester 2012, p. 3, emphasis added)
}

It appeared that we knew what we wanted our DHSc to tackle. Rather than these authors telling us how a professional doctorate needed to work, in their definition we found similarities with our own thinking (Smythe \& Spence 2012). Now, we were looking for other voices to validate 
the view from our horizon. We particularly agreed on Jones's (2018, p. 823) notion that developing expert researchers with a narrow scope and 'limited contribution to practice' did not work with the PhD approach. He viewed the professional doctorate as comparatively better fitted to the needs of industry (in our case, the healthcare setting), enabling universities to be perceived as offering academic and practical relevance, and, thus, attracting a greater number of candidates. Meanwhile, Robinson's (2018, p. 96) contention also held true, in that candidates undertaking a professional doctorate are more likely to decide their own topic of exploration, with 'the potential to make a difference within their own institutional settings'. Lunt (2018) also drew attention to the researcher as the instrument, embarking on a deeply reflexive project embedded in practice. Burnard, Dragovi and Ottewell (2018, p. 42) put it this way: 'the researching professional is part of that which is being researched ... co-constructing new relationships between theory and practice'.

We also found insight from Costely and Pizzolato (2018, p. 37), who stated that:

\footnotetext{
'in DProf programmes the practitioner undertaking the research is often the person who also then develops the outcome in the work setting, frequently along with other colleagues. Alternatively, the research project seeks to persuade others to make tangible changes.'
}

The more we read (Boud et al. 2018; Buss 2017; Hawkes \& Yerrabati 2008; Pratt et al. 2014), the more understandings revealed common-held threads. One paper cited another, building evidence and creating a shared vision. The 'saying' (Kemmis 2009) of professional doctorate practice, while drawing on a variety of words and definitions, emerged as a distinctive discourse about creating a space where practitioners can engage in the sort of 'research' that has relevance to them and their stakeholders. When we are clear in what we articulate, we are more likely to translate that to how we go about doing things. The tension arises in the reality of practices being socially formed. Like others, we encountered discord in having theses misunderstood by those not familiar with the nature of a professional doctorate. Examiners brought a PhD mindset to the examination (Maxwell \& Kupczyk-Romanczuk 2009; Rolfe \& Davies 2009), and this heightened awareness of the need to identify those who were likely to share the horizon of understanding presented by a candidate. Unfortunately, these numbers are small in the health sector. Nonetheless, the literature informed our program, both by leading us forwards and by giving us the confidence to continue on ways that had already emerged. It confirmed the understanding we had developed through our own experience, and gave us the courage to continue to develop a more 
practice-based approach. That said, the most powerful shapers of change were the candidates themselves.

\section{DISTINGUISHING WHAT CANDIDATES WANT FROM A PROFESSIONAL DOCTORATE}

The complex demands on candidates enrolling in the DHSc are often different from those of PhD candidates. Our DHSc candidates are all fully employed and typically face additional family pressures. They undertake the DHSC along with other responsibilities and demands on their own time. Many already hold significant leadership and management positions, so the program is often viewed as a pathway leading to promotion during the course of their study. Indeed, something draws them to want to enrol in our DHSc; we recall no one candidate who was sent to register. Making such a commitment in an already busy life reflects who they are, often with delight in the possibility of changing practice for the betterment of clients and staff, and community and profession. Essentially, these individuals have no appetite for doing research that is not directly relevant to their own domain of practice.

\section{WHAT AND HOW WE TEACH}

The candidates who come to the DHSc are colleagues from both practice and university. They bring with them many possible interests and concerns from practice, long before they have read the related literature: their mandate is to initiate and lead change. Three papers (modules) guide them to their thesis. 'Practice and Philosophies' reawakens them to the assumptions and methods of a wide variety of research methodologies; 'Health Systems Analysis' asks them to situate their issue of interest in the relevant social, political and cultural context; and the third paper, 'Research Practice and Methodology', supports them in writing their research proposal. Learning outcomes are designed to enable the candidate to work towards productive contributions to their journey, whether that involves publications or the beginnings of thesis chapters.

We have come to appreciate the importance of the leadership thread through these three papers. We do not 'teach' leadership; rather, we engage candidates in a process that encourages them to see how moments of being the 'leader' have emerged through their life story. These insights have ultimately proven to be transformational in building confidence and in recognising one's 'self'.

Our pedagogy stems from a place that acknowledges how these candidates are already experts and already leaders. This engenders a relationship of respect and recognition that they do not need to be taught, but rather drawn into thinking (Smythe, Rolfe \& Larmer 2016). Candidates are brought together for a week to complete the first two papers and to expose them to the stories of a range of researchers and leaders. PowerPoint presentations are discouraged, as 
conversation, questions and anything that encourages thinking is preferred (Heidegger 1968). The pedagogy that has emerged has been heavily influenced by Heideggerian hermeneutics, which suggests the role of the teacher is 'to learn to let them [the candidates] learn' (Heidegger 1968, p. 15). As Heidegger (1966, p. 52) further explains:

'it is one thing to have heard and read something, that is, merely to take notice; it is another thing to understand what we have heard and read, that is, to ponder.'

We too encourage pondering by inviting candidates to write (or draw) their thinking in a non-academic way for the purpose of letting their thinking emerge, free from the constraints of referencing. The formal writing follows, crafting insights that arise from pondering into a scholarly argument. By the third paper, the candidates are ready to write their thesis proposal. All through the other two papers we constantly signal the different ways in which research can bring about change.

\section{MODES OF PRACTICE-LED RESEARCH}

Our emergent insights into the nature of a professional doctorate show us that while practice issues primarily drive theses, not all embrace research methodologies that are directed towards change. However, we have also witnessed that change can occur in every thesis experience. Table 1 differentiates the three modes of approach. As shown, the 'research on practice' phase is where a researcher does not directly collect data from their own practice community. As the candidate is embedded in a related domain of practice, they themselves enact the recommendations. Conversely, 'research IN practice' takes on an action-research type approach for the specific purpose of bringing about change. Even though both transpire within a practice setting, individuals function in a researcher role. At the centre of our DHSc experience is research, which happens at the 'nexus' of research and practice. This is where the candidate is both a paid employee with a mandate to lead change, and seeks to make said change the focus of their thesis. Tension arises when employees have little choice but to participate in the change process, making the informed consent of formal research and the likely power differentials challenging. The method used to make this work is to focus the research component on the reflective analysis of the change process. of all the modes, this is perhaps the most transformational experience for the candidate, as they can critique their leadership skills and strategies. 


\section{RECOGNISING THE DISTINGUISHING CHARACTERISTICS BETWEEN A PHD AND A PROFESSIONAL DOCTORATE}

Some of our DHSc candidates chose to do a mixed-methods research project because their goal was to gather evidence that will drive change. Conversely, others chose a methodology such as phenomenology because they wanted to first understand 'the experience'; indeed, such theses would be difficult to distinguish from a PhD. Some candidates embarked creatively on an action-research project, which, again, is equally appropriate to a PhD. Perhaps the key difference is found in those candidates who stand amid the tension between 'practice and research', and seek to find insights from the interplay. Hence, Table 2 draws on our understandings from the literature and expands it from our own experience. The arrows indicate the key areas of difference, recognising that every thesis has the potential to move either way. Essentially, it concludes that a professional doctorate:

- is always practice-led

- comes with a commitment towards change, whether in the process of or following change

- offers the candidate an interprofessional experience of learning together

- seeks to promote opportunities through which each candidate comes to flourish as the leader they are.

\section{CONCLUSION}

In offering this reflective analysis drawn from our own experience during the maturation of our DHSC program, we recognise that we have moved from discussing the ethos of a professional doctorate to living the experience. While we may have created the space to explore possibilities, it was our candidates who courageously took on the challenge to embed their research within their own practice domain. They challenged the status quo, took risks and proceeded with no clear guide to follow. For this, we salute their pioneering spirit: they have made the DHSc what it has become. This program is now marketed to stakeholders and candidates as a means of making tangible change in the real world of practice. As supervisors, we have encouraged them, been open to possibilities, walked alongside them into the unknown and trusted that the outcome would be successful. Evidently, the key success factors include having witnessed practice change as a direct result of a candidate's research, and observing individuals move into their leadership potential, winning prestigious scholarships and receiving promotions to high-level appointments. The purpose of sharing our story is to show others how altering one's mindset with a resultant change of practice is a progressive journey of understanding, as well as a valuable 
challenge. Change, then, comes from the voices and actions of many, such as international colleagues through conferences and writing, team discussions, input from stakeholders, and, most of all, from the candidates themselves. It is they who know best what will most usefully serve their needs as leaders within the health sector. Thus, the responsibility lies with us, the educators, to rise up and play our part in effectively preparing the leaders of today and the future.

Acknowledgements

We would like to acknowledge all our candidates and

colleagues who have been on this journey with us.

Conflict of Interest

The authors declare no potential conflicts of interest

with respect to the research, authorship and/or

publication of this article.

Funding

This research received no specific grant from any funding agency • 
References

Boud, D, Fillery-Travis, A, Pizzolato, N \& Sutton, B 2018, 'The influence of professional doctorates on practice and the workplace', Studies in Higher Education, vol. 43, no. 5, pp. 914-926.

Burnard, P, Dragovic, T \& Ottewell, K, Lim, WM 2018, 'Voicing the professional doctorate and the researching professional's identity: Theorizing the EdD's uniqueness', London Review of Education, vol. 16, no. 1, pp. 40-55.

Buss, RR, Zambo, R, Zambo, D, Perry, JA \& Williams, TR 2017, 'Faculty members' responses to implementing reenvisioned EdD programs', Studies in Higher Education, vol. 42, no. 9, pp. 1624-1640.

Costley, C \& Lester, S 2012, 'Work-based doctorates: Professional extension at the highest levels', Studies in Higher Education, vol. 37, no. 3, pp. 257-269.

Costley, C \& Pizzolato, $N$ 2018, 'Transdisciplinary qualities in practice doctorates', Studies in Continuing Education, vol. 40, no. 1, pp. 30-45.

Fish, D 2009, 'Research pragmatic practice: Unpredictable means, unforeseeable ends', in B Green (ed.), Understanding and researching professional practice, sense Publishers, Rotterdam, pp. 131-155.

Hawkes, D \& Yerrabati, S 2018, 'A systematic review of research on professional doctorates', London Review of Education, vol. 16, no. 1, pp. 10-27.

Heidegger, M 1966, Discourse on thinking, trans. JM Anderson \& EH Freund, Harper and Row, New York.

Heidegger, M 1968, What is called thinking? trans. JG Gray, Harper and Row, New York.

Jones, M 2018, Contemporary trends in professional doctorates', Studies in Higher Education, vol. 43, no. 5, pp. $814-825$.

Kemmis, S 2009, 'Understanding professional practice: A synoptic framework', In B Green (ed.), Understanding and researching professional practice, sense Publishers, Rotterdam, pp. 19-38.

Lunt, I 2018, 'Introduction to 'the EdD at 20: Lessons learned from professional doctorates': A special feature for the London Review of Education', London Review of Education, vol. 16, no. 1, pp. 4-9.

Maxwell, TW \& Kupczyk-Romanczuk, G 2009, 'Producing the professional doctorate: The portfolio as a legitimate alternative to the dissertation', Innovations in Education and Teaching International, vol. 46, no. 2, pp. 135-145. Pratt, N, Tedder, M, Boyask, R \& Kelly, P 2014, 'Pedagogic relations and professional change: A sociocultural analysis of students' learning in a professional doctorate', Studies in Higher Education, vol. 40, no. 1, pp. 43-59.

Robinson, C 2018, 'The landscape of professional doctorate provision in English higher education institutions: Inconsistencies, tensions and unsustainability', London Review of Education, vol. 16, no. 1, pp. 90-103.

Rolfe, G \& Davies, R 2009, 'Second generation professional doctorates in nursing', International Journal of Nursing Studies, vol. 46, no. 9, pp. 1265-1273. 
Smythe, E, Rolfe, G \& Larmer, P 2016, 'Learning to think in the corporate university: Developing a doctorate for practice', in VA Storey (ed.), International perspectives on designing professional practice doctorates: Applying the critical friends approach to the EdD and beyond, Palgrave MacMillan, New York, pp. 99-113.

Smythe, E\& Spence, D 2012, 'Re-viewing literature in hermeneutic research', International Journal of Qualitative Methods, vol. 11, no. 1, pp. 12-25.

99. Link 
Table 1: Modes of practice-led research

Modes of practice-led research

Research ON practice
Description of how such research leads to change

Candidates take on the researcher role removed from any work-related position. They make recommendations from findings, and personally enact these due to the relevance to their own practice setting.

Flood, B 2017, 'Toward a spirit of interprofessional practice: A hermeneutic phenomenological study', doctoral thesis, Auckland University of Technology, Auckland, http://hdl.handle.net/10292/10776.

Brenda interviewed practitioners about their experience working interprofessionally. The insights from her thesis have since deeply informed her leadership in initiating interprofessional learning activities at the School of Clinical Science at AUT. The 'change' followed.

Candidates take on an action-research type approach and work directly with colleagues

Research IN practice from practice. However, they do this in the role of 'researcher'. Change happens in practice through the action cycles, and often extends beyond thesis submission.

Austin, D 2017, 'Facilitating health professional wellbeing following critical incidents: An action research study', doctoral thesis, Auckland University of Technology, Auckland, http://hdl.handle.net/10292/10947.

Diana worked with stakeholders to discover a better way to support staff after a critical incident. With their input, she developed an ebook that became available to all staff before her thesis was submitted. 'Change' was a focus of the research.

Candidates hold the tension of being both researcher and employee. Clear distinction

Research at the nexus needs to be made in defining the 'research' component. Issues of informed consent may limit what counts as 'research'.

Chadwick, M 2018, 'Leading health workforce change: Insights from experience', doctoral thesis, Auckland University of Technology, Auckland http://hdl.handle.net/10292/12033.

Martin was the manager of a large health service seeking to make change. He led action cycles as part of his employment. For his thesis, Martin described the change process he had initiated, sought evaluative interviews with some participants months after initiation, and wrote his thesis as a reflective analysis of his leadership. From this, he created a model of the different philosophical approaches needed at specific phases of the change process. 'Change' was in the partnerships established throughout the research process. 
Candidate seeks a career in research at university. They

Purpose

want to become an expert researcher.
Candidate works as a practitioner in health or an educator of health students. They wish to do research that directly affects practice, and want to lead change.

$\begin{array}{cc}\text { Candidate seeks to grow a } & \text { Nurture candidates' leadership } \\ \text { research career, most likely at at } & \text { skills within their domain of } \\ \text { a university: research } & \text { practice and supervise others } \\ \text { dominates. } & \text { on similar quests: practice } \\ \text { dominates. }\end{array}$

\begin{tabular}{|c|c|c|}
\hline Genesis of research topic & $\begin{array}{l}\text { Candidates come with an } \\
\text { interest (which may be from } \\
\text { practice) and turn to the } \\
\text { literature to discern the 'gap' } \\
\text { that has not yet been } \\
\text { researched. } \\
\text { Their prime goal is to make a } \\
\text { contribution to knowledge. }\end{array}$ & $\begin{array}{l}\text { Candidates come with issues } \\
\text { or possibilities arising from their } \\
\text { practice. They are committed to } \\
\text { research that will likely bring } \\
\text { about change. } \\
\text { Their primary goal is to make a } \\
\text { contribution to practice. }\end{array}$ \\
\hline
\end{tabular}

The initial research question The dynamic and emergent determines the breadth of nature of practice means focus, guiding the literature that a robust research review, informing the design proposal either may not be and ensuring the findings possible or changes are congruent with the throughout the course of the research question. research. Other issues or

Scope of focus

The scope of focus is predetermined in the research possibilities may eventually proposal. take priority. The candidate reads and researches in response to what the context demands.

The focus is open to change and responds as necessary to circumstances.

The thesis is presented in a The thesis tells the story of the
traditional format. The research. It describes the
research question is impetus and the original plan,
supported by a focused and how that may have
literature review. The design changed. The literature review
is methodologically sound, indicates it has emerged over
the course of the research, as


and the findings are

priorities altered. The findings

congruent with the original are directly relevant to practice

research question.

The contribution to knowledge is explicit. and may have already been adopted. The contribution to knowledge is drawn from the practice focus.

The candidate recognises their The candidate recognises their growing expertise in conducting development as a leader and research and in the topic under change agent. Through investigation. negotiation with stakeholders, working the participants, dwelling on the data and

Personal and professional development

bringing the recommendations back to practice, they grow confidence in how their research can affect the 'real world'.

The experience is likely to be a Candidates are part of a cohort solo journey, supported by supervisors from which support groups emerge. They learn from each other and build strong

Learning experience interprofessional networks. Candidates return as graduates to inspire current cohorts, becoming part of a community of leaders. 